\title{
PERENCANAAN TEBAL PERKERASAN KAKU JALAN TEMBILAHAN - TERUSAN MAS
}

\author{
Maya Sari ${ }^{1}$, Jusatria ${ }^{2}$, Surya Adinata ${ }^{3}$ \\ 1,2Program Studi Teknik Sipil Universitas Islam Indragiri, Tembilahan \\ ${ }^{3}$ Program Studi Teknik Sipil Universitas Islam Kuantan Singingi \\ Email: mayaasarii12@gmail.com (korespondensi)
}

\begin{abstract}
Roads are one of the transportation infrastructure facilities that have an important role in supporting the smoothness of land transportation. In terms of infrastructure, the main connecting road must provide a quality level of service, this is influenced by the condition of the road structure, so, road improvements are needed in terms of quality and quantity. The improvement of the Tembilahan - Terusan Mas road cannot be separated from the value of pavement thickness planning because the pavement thickness planning stage must consider about economic factors, subgrade, traffic loads, road functions and other factors. The pavement thickness planning for Tembilahan - Terusan Mas road uses rigid pavement. This planning analysis uses the Bina Marga method (component analysis method) because this method is considered quite widely used in pavement thickness planning such as conditions in Indonesia.Pavement thickness planning in this final project will discuss the value of rigid pavement thickness and cost budget using the Bina Marga method. Analysis of the rigid pavement design obtained that the thickness of the $K-350$ concrete slab is $20 \mathrm{~cm}$, the $\mathrm{K}-125$ concrete sub-base layer is $15 \mathrm{~cm}$, with a budget of Rp. 25,035,692,000.00.
\end{abstract}

Keywords: Road, Rigid Pavement, Budget Plan

\begin{abstract}
Abstrak
Jalan merupakan salah satu sarana prasarana transportasi yang memiliki peranan penting dalam menunjang kelancaran transfortasi darat. Dalam sarana prasarana penghubung utama jalan harus memberikan tingkat pelayanan yang berkualitas, hal ini dipengaruhi oleh kondisi struktur jalan tersebut, maka dibutuhkan peningkatan jalan dari segi kualitas dan kuantitas. Peningkatan jalan Tembilahan - Terusan Mas tidak lepas dari nilai perencanaan tebal perkerasan karena tahap perencanaan tebal perkerasan harus mempertimbangkan faktor ekonomi, tanah dasar, beban lalu-lintas, fungsi jalan dan faktor-faktor lainnya. Perencanaan tebal perkerasan pada jalan Tembilahan - Terusan Mas menggunakan perkerasan kaku. Analisa perencanaan ini menggunakan metode Bina Marga (metode analisa komponen) karena metode ini dirasakan cukup banyak digunakan dalam perencanaan tebal perkerasan seperti kondisi di Indonesia. Perencanaan tebal perkerasan dalam tugas akhir ini akan dibahas nilai ketebalan perkerasan kaku dan anggaran biaya dengan menggunakan metode Bina Marga. Analisa dari perencanaan perkerasan kaku diperoleh tebal pelat beton $\mathrm{K}$ - 350 adalah $20 \mathrm{~cm}$, lapisan pondasi bawah beton $\mathrm{K}-125$ adalah $15 \mathrm{~cm}$, dengan anggaran biaya sebesar Rp. 25.035.692.000,00.
\end{abstract}

Kata kunci: Jalan, Perkerasan Kaku, Rencana Anggaran Biaya

\section{PENDAhuluan}

Transportasi umum adalah seluruh alat transportasi saat penumpang tidak berpergian menggunakan kendaraan sendiri. Transportasi umum pada umumnya termasuk kereta api dan bis, namun juga termasuk pelayanan maskapai penerbangan, feri, taksi dan lain-lain. Transportasi dibedakan menjadi tiga yaitu: Transportasi Darat, Air, dan Udara.

Jenis konstruksi perkerasan jalan pada umumnya ada 2 (dua) jenis, yaitu Perkerasan lentur (flexible pavement), dan Perkerasan kaku (rigid pavement). Jenis perkerasan dibedakan berdasarkan bahan pengikatnya yaitu : Perkerasan lentur (flexible pavement) yaitu konstruksi 
perkerasan yang menggunakan aspal sebagai bahan pengikatnya. Lapisan-lapisan perkerasan bersifat memikul dan menyebarkan beban roda ke tanah dasar. Perkerasan kaku (rigid pavement) yaitu konstruksi perkerasan yang menggunakan semen sebagai bahan pengikatnya, pelat beton dengan atau tanpa tulangan diletakkan di atas tanah dasar dengan atau tanpa pondasi bawah, pelat tersebut yang memikul sebagian besar beban roda lalu lintas.

Mengingat kondisi ruas jalan Tembilahan - Terusan Mas yang saat ini menggunakan perkerasan lentur mempunyai ketinggian dibawah tinggi maksimum air pasang yang terjadi dikota Tembilahan ini yang membuat ruas jalan selalu terendam air pasang dan menyebabkan kerusakan pada perkerasan jalan. Perkerasan dengan menggunakan aspal di rasa kurang cocok untuk digunakan pada jalan Tembilahan - Terusan Mas ini, karena ruas jalan ini difungsikan untuk melayani lalu-lintas yang padat dengan beban kendaraan yang cukup besar, jalan ini merupakan akses utama keluar masuknya barang/jasa kepusat Kota Tembilahan dan sekitarnya, serta keberadaan jalan Tembilahan - Terusan Mas berdekatan dengan kawasan Industri Pembangkit Listrik Tenaga Uap (PLTU) dan Dermaga Parit 21 (dua puluh satu), dan kondisi jalan yang selalu terkena genangan air pasang menyebabkan aspal menjadi mudah rusak (berlubang maupun bergelombang) jika terus dilalui kendaran yang memiliki beban berat.

\section{LANDASAN TEORI}

\subsection{Perkerasan Jalan Raya}

Perkerasan jalan raya adalah bagian jalan raya yang diperkeras dengan lapis konstruksi tertentu, yang memiliki ketebalan, kekuatan, dan kekakuan, serta kestabilan tertentu agar mampu menyalurkan beban lalu lintas diatasnya ke tanah dasar secara aman. Perkerasan jalan merupakan lapisan perkerasan yang terletak di antara lapisan tanah dasar dan roda kendaraan, yang berfungsi memberikan pelayanan kepada sarana transportasi, dan selama masa pelayanannya diharapkan tidak terjadi kerusakan yang berarti. Perkerasan jalan yang sesuai dengan mutu yang diharapkan, maka pengetahuan tentang sifat, pengadaan dan pengolahan dari bahan penyusun perkerasan jalan sangat diperlukan. (Silvia Sukirman, 2003).

Perkerasan merupakan bagian dari perencanaan jalan yang direncanakan dapat memberikan tingkat pelayanan yang tinggi bagi lalu lintas yang lewat serta menghasilkan efisiensi, keamanan, kenyamanan yang paling optimal, namun tujuan agar tersedianya jalan yang mempunyai standar mutu yang tinggi sesuai dengan fungsinya, artinya dapat menyediakan lapisan perkerasan jalan yang berlapis dengan susunan tertentu.

\subsection{Kriteria Perencanaan}

Jalan memiliki syarat umum yaitu dari segi konstruksi harus kuat, awet dan kedap air. Jika dilihat dari segi pelayanan, jalan harus rata, tidak licin, geometrik memadai dan ekonomis. Untuk itu, dibutuhkan suatu rancangan perkerasan yang mampu melayani beban berupa lalu-lintas yang melewati perkerasan tersebut.

1. Klasifikasi Jalan
a. Klasifikasi menurut fungsi jalan ( MKJI )
b. Klasifikasi menurut kelas jalan
c. Klasifikasi menurut medan jalan
d. Klasifikasi menurut wewenang pembinaan
e. jalan

2. Bagian-Bagian Jalan
a. Ruang Manfaat Jalan
b. Ruang Milik Jalan
c. Ruang Pengawasan Jalan

\subsection{Jenis Konstruksi Perkerasan dan Komponennya}

1. Fungsi Lapis Perkerasan
a. Lapis Permukaan (LP)
b. Lapis Pondasi Atas (LPA) atau Base Course
c. Lapis Pondasi Bawah (LPB) atau Subbase Course
d. Tanah Dasar (TD) atau Subgrade
e. Penyebaran Gaya Pada Perkerasan

2. Konstruksi Perkerasan Lentur (Flexible Pavement)

3. Konstruksi Perkerasan Komposit (Composite Pavement)

4. Konstruksi Perkerasan Kaku (Rigid Pavement)

a. Fungsi dan Jenis Lapisan Perkerasan Kaku

b. Jenis Perkerasan Kaku

c. Penyalur Beban

d. Baja Tulangan (Wire Mesh)

e. Sambungan (joint)

f. Pengisi Sambungan dan Penutup Sambungan (Joint Filter and Joint sealer)

\subsection{Parameter Perencanaan Tebal Perkerasan Kaku Berdasarkan Metode Bina Marga}

Parameter-parameter yang digunakan dalam merencanakan perkerasan kaku 
meliputi: tanah dasar, pondasi bawah, kekuatan beton, Lalu-lintas, lalu lintas rencana, faktor pertumbuhan lalu-lintas, umur rencana, persentase beban sumbu, jumlah repetisi yang akan terjadi selama umur rencana, lajur rencana dan koefisien distribusi (c), faktor keamanan beban, besaran - besaran beban sumbu, perbandingan tegangan dihitung dengan membagi tegangan lentur yang terjadi pada pelat dengan modulus keruntuhan lentur beton $\mathrm{MR}_{28}$, jumlah pengulangan beban yang diijinkan ditentukan berdasarkan harga perbandingan tegangan pada tabel 1 .

Tabel 1 Perbandingan Tegangan dan Jumlah Pengulangan Beban Yang Diijinkan

\begin{tabular}{|c|c|c|c|}
\hline $\begin{array}{c}\text { Per } \\
\text { bandin } \\
\text { gan } \\
\text { tegang } \\
\text { an a }\end{array}$ & $\begin{array}{c}\text { Jumlah } \\
\text { pengulan } \\
\text { gan } \\
\text { beban } \\
\text { ijin }\end{array}$ & $\begin{array}{c}\text { Perbandin } \\
\text { gan } \\
\text { tegangan }\end{array}$ & $\begin{array}{c}\text { Jumlah } \\
\text { pengulan } \\
\text { gan } \\
\text { beban } \\
\text { ijin }\end{array}$ \\
\hline $0,51^{b}$ & 400.000 & 0,69 & 2.500 \\
\hline 0,52 & 300.000 & 0,70 & 2.000 \\
\hline 0,53 & 240.000 & 0,71 & 1.500 \\
\hline 0,54 & 180.000 & 0,72 & 1.000 \\
\hline 0,55 & 130.000 & 0,73 & 850 \\
\hline 0,56 & 100.000 & 0,74 & 650 \\
\hline 0,57 & 75.000 & 0,75 & 490 \\
\hline 0,58 & 57.000 & 0,76 & 360 \\
\hline 0,59 & 42.000 & 0,77 & 270 \\
\hline 0,60 & 32.000 & 0,78 & 210 \\
\hline 0,61 & 24.000 & 0,79 & 160 \\
\hline 0,62 & 18.000 & 0,80 & 120 \\
\hline 0,63 & 14.000 & 0,81 & 90 \\
\hline 0,64 & 11.000 & 0,82 & 70 \\
\hline 0,65 & 8.000 & 0,83 & 50 \\
\hline 0,66 & 6.000 & 0,84 & 40 \\
\hline 0,67 & 4.500 & 0,83 & 30 \\
\hline 0,68 & 3.500 & & \\
\hline
\end{tabular}

Keterangan :

a Tegangan akibat beban dibagi dengan

kekuatan lentur tarik (modulus of

Rupture).

b Untuk perbandingan tegangan $\leq 0,50$

jumlah pengulangan beban adalah tidak terhingga.

Persentase lelah (fatigue), total fatigue, tebal pelat beton yang dipilih/ditaksir dinyatakan sudah benar/cocok apabila total fatigue yang didapat besarnya lebih kecil atau sama dengan $100 \%$.

\subsection{Parameter Perencanaan Ruji, Batang Pengikat, dan Tulangan Berdasarkan Metode Bina Marga}

Parameter-parameter yang digunakan untuk merencanakan ruji, batang pengikat, dan tulangan meliputi:
1. Diameter Ruji dan Batang Pengikat

2. Luas penampang tulangan

3. Koefisien Gesekan (F)

4. Presentasi luas tulangan yang dibutuhkan terhadap luas penampang beton. Digunakan untuk perhitungan Beton Menerus Dengan Tulangan (BMDT).

\subsection{Beban Lalu Lintas}

Data lalu - lintas adalah data utama yang diperlukan untuk perencanaan teknik jalan, karena kapasitas jalan yang akan direncanakan tergantung dari komposisi lalu - lintas yang akan menggunakan jalan pada suatu segmen jalan yang ditinjau. Besarnya volume atau arus lalu - lintas diperlukan untuk mementukan jumlah dan lebar lajur pada satu jalur jalan dalam penentuan karakteristik geometri, sedangkan jenis kendaraan akan menentukan kelas beban atau MST (Muatan Sumbu Terberat) yang berpengaruh langsung pada perencanaan konstruksi perkerasan.

Data dan parameter lalu-lintas yang digunakan untuk perencanaan tebal perkerasan meliputi Jenis kendaraan.

\subsection{Pertimbangan Ekonomi}

Dalam setiap pembangunan, analisis perhitungan biaya yang dikeluarkan untuk setiap proyek harus mencapai persyaratan ekonomis, terlebih lagi untuk proyek peningkatan jalan yang diperoleh berbagai anggapan dalam perhitungan biaya yang digunakan, antara lain adalah umur rencana, laju pertumbuhan lalu lintas dan tujuan dari pembina jalan. Semua biaya yang menyangkut aspek tersebut digunakan dalam analisis perhitungan biaya sesuai dengan fungsi dan tipe pekerjaan jalan.

\subsection{Dasar-dasar Perencanaan}

Dalam perhitungan perencanaan perkerasan kaku (rigid pavement) ini mengacu pada standar yang sudah biasa digunakan untuk perencanaan perencanaan beton semen indonesia. Standar tersebut antara lain :

1. Penetapan ruas jalan dalam jaringan jalan primer menurut fungsinya sebagai Jalan Arteri (JAP) dan Jalan Kolektor -1 (JKP-1),

2. Perencanaan Perkerasan Jalan semen. Departemen Pemukiman dan Prasarana Wilayah. (Pd T-14-2003),

3. Perkerasan JalanSemen Portland (Rigid Pavement) Perencanaan Metode AASHTO 1993.

\subsection{Penyusunan Rencana Anggaran Biaya}


Penyusunan anggaran biaya penulis menggunakan teori-teori umum yang dipakai dalam penyusunan anggaran biaya. Setelah mendapatkan tebal perkerasan dalam setiap jenis perkerasan di cari volume pekerjaan berdasarkan data teknis jalan dan tebal perkerasan itu sendiri.

Penyusunan anggaran biaya untuk tebal perkerasan Pada Ruas Jalan Tembilahan Terusan Mas menggunakan analisa harga satuan pekerjaan Engineers Estimate (EE) Dinas Pekerjaan Umum Bidang Bina Marga tahun 2021.

\subsection{Pengaruh Musim hujan}

Perencana perkerasan harus mempertimbangkan implikasi musim hujan terhadap aktivitas pelaksanaan terutama di daerah rendah yang cenderung menjadi jenuh selama musim hujan. Karena pada umumnya tidak ada jaminan bahwa pelaksanaan konstruksi dapat dilaksanakan pada musim kemarau, pertimbangan desain hendaknya didasarkan pada kondisi tanah dasar saat musim hujan.

\subsection{Pengaruh Air Pasang}

Material pembentuk perkerasan jalan, umumnya sangat dipengaruhi oleh faktor kelembaban (kadar air) dan lingkungan. Kadar air yang berlebihan akibat tergenang air terlalu lama di dalam struktur perkerasan, umumnya akan berakibat buruk pada kinerja perkerasan. Hal ini, karena kenaikan kelembaban atau kadar air akan mereduksi kekuatan dan kekakuan material granuler (tak terikat), pengembangan tanahdasar. Selain itu, material granuler (lapis pondasi dan pondasi bawah tanah) menjadi terkotori oleh butiran halus dari tanah dasar yang ter-pompa ke atas bersama air. Pembahasan relatif lama pada tanah dasar mengurangi daya dukung tanah dasar, dengan demikian mengurangi kinerja jangka panjang struktur perkerasan.

Pada tanah-dasar, kelembaban atau kadar air mempengaruhi (FHWA, 2006):

a. Kedudukan tegangan yaitu oleh pengaruh isapan dan tekanan air pori. Material berbutir kasar dan halus, dapat mempunyai modulus pada kondisi kering sampai lima kali, dari ketika material tersebut basah Terutama, modulus lempung sangat dipengaruhi oleh perubahan kadar air (bila kadar air naik, modulusnya turun).

b. Susunan tanah melalui gangguan sementasi antara partikel-partikel tanah

\section{METODOLOGI PENELITIAN}

Perencanaan jalan sebelum direncanakan perlu dilakukan proses analisa dari informasi data-data mengenai objek yang akan kita rencanakan. Hal ini perlu dilakukan dengan cermat dan teliti, serta di dukung dengan dasar-dasar teori dan perlengkapan yang memadai sehingga di dapat hasil yang baik.

Agar memudahkan dalam penulisan Tugas Akhir ini disajikan Flow chart sebagai berikut:

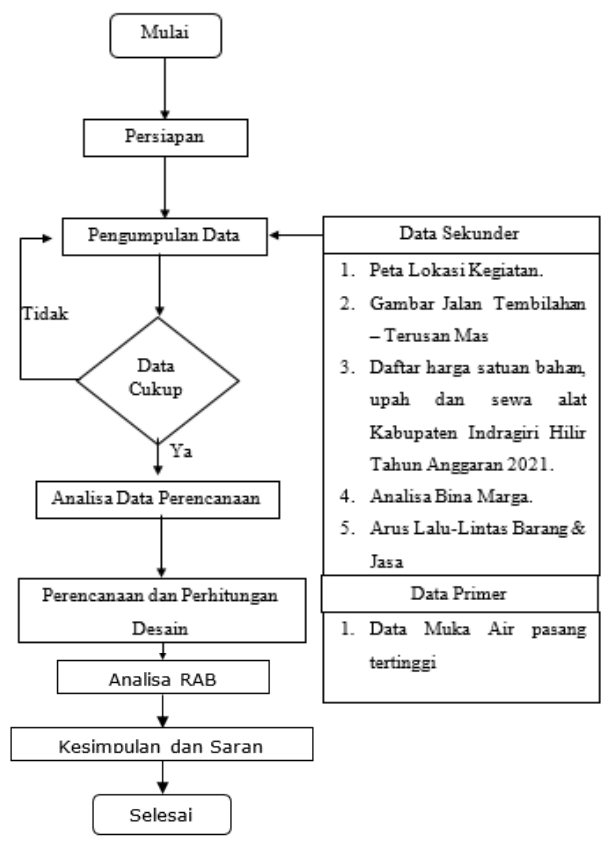

Gambar 1. Flow Chart Penyusunan Tugas Akhir Perencanaan Tebal Perkerasan Pada Ruas Jalan Tembilahan - Terusan Mas. (Sumber : Hasil analisis)

\section{ANALISA DAN PEMBAHASAN}

\subsection{Gambaran Umum Wilayah Tinjauan}

Kabupaten Indragiri Hilir atau wilayah Tembilahan resmi menjadi daerah tingkat II berdasarkan Undang-Undang No. 6 Tahun 1965 tanggal 14 Juni 1965 (LN RI No.49) daerah ini terletak dibagian selatan Provinsi Riau dengan luas wilayah $11.605,97 \mathrm{Km}^{2}$ dalam posisi : $0^{0} 36^{\prime}$ Lintang Utara, $1^{0}$ 07' Lintang Selatan $104^{\circ} 10^{\prime}$ Bujur Timur dan $102^{\circ} 32^{\prime}$ Bujur Timur dan untuk luas wilayah untuk Kecamatan Tembilahan sendiri adalah 197,37 $\mathrm{Km}^{2}$. (sumber :BPS Kabupaten Indragiri Hilir ).

Pertumbuhan Kota Tembilahan sangat dipengaruhi oleh pertumbuhan wilayahwilayah disekitarnya, sehingga sangat besar pengaruhnya pada peran dan4 fungsi kota sebagai bagian dari wilayah perkotaan. Jasa perdagangan yang berkembang relative cepat oleh karena memiliki jaringan jalan 
ragional yang menghubungkan beberapa pusat pertumbuhan ekonomi.

Jalan Tembilahan - Terusan Mas merupakan jalan yang seharusnya sangat diperhatikan karena dapat memberikan pengaruh yang cukup besar terhadap pertumbuhan dan perkembangan didaerah tersebut sehingga menjadi arti penting dalam sistem pembangunan dan tata ruang wilayah kota.

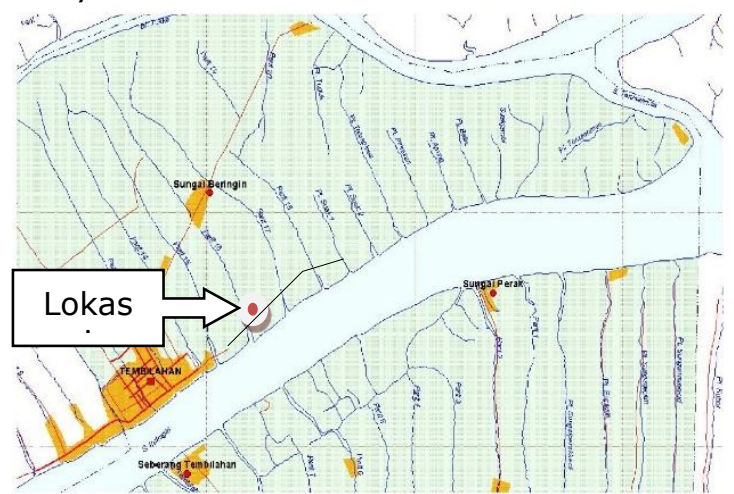

Gambar 2. Peta Kecamatan Tembilahan Sumber : Dinas Pekerjaan Umum dan Tata Ruang Kab.

\subsection{Analisa} Inhil)

Perhitungan Analisa perencanaan tebal perkerasan pada ruas jalan TembilahanTerusan Mas terdiri dari 2 (dua) tahap yaitu:

1. Analisa Perencanaan Tebal Perkerasan Kaku.

2. Analisa Anggaran Biaya.

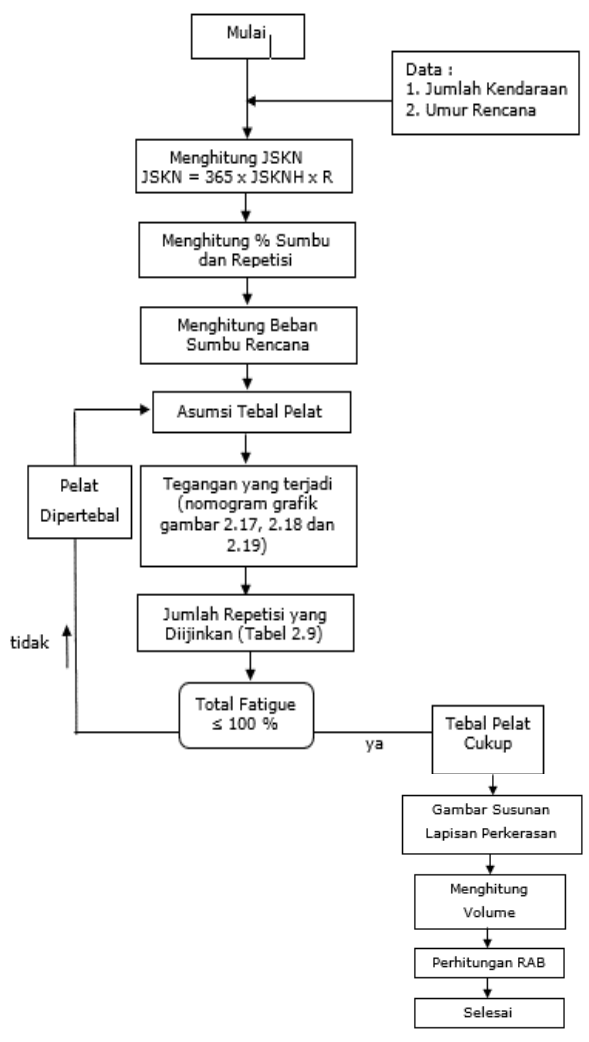

Gambar 3. Flow Chart Perencanaan Tebal Perkerasan Kaku.

(Sumber : Data analisis)

\subsubsection{Teknis Perencanaan Tebal Perkerasan Kaku}

Data teknis yang dipergunakan dalam perencanaan tebal perkerasan kaku ini adalah sebagai berikut :

a. Umur rencana : 20 Tahun

b. Koefisien Distribusi Jalur (c) : 0,50 (Tabel 2.7)

c. Pertumbuhan lalu-lintas : $8 \%$ Per tahun

d. Peranan jalan : Jalan lokal

e. Tipe jalan : 2 jalur 2 arah

Besarnya LHR (Lalu-lintas harian ratarata) didapat dari jumlah arus lalu lintas pada suatu titik ruas pada lokasi pengamatan, sehingga dapat memberi gambaran tentang variasi volume lalulintas menurut waktu pada keadaan jam sibuk. Menitik beratkan lintas harian rata-rata harian sebagai tolak ukur perkembangan lalu lintas yang terjadi persatuan jam. Sehingga didapat total lalu lintas harian 2021 pada tabel 2 :

Tabel 2 Perhitungan Lalu Lintas Harian

\begin{tabular}{|c|c|c|c|c|}
\hline \multicolumn{5}{|c|}{ Rata - Rata } \\
\hline No. & $\begin{array}{c}\text { Jenis } \\
\text { Kendaraan }\end{array}$ & $\begin{array}{c}\text { Volume } \\
\text { Jam } \\
\text { Rencana } \\
\text { (Jam) }\end{array}$ & $1 / \mathrm{K}$ & Jumlah \\
\hline 1 & S. Motor & 718 & 11,11 & 7981.5 \\
\hline 2 & Mobil & 99 & 11,11 & 1101.2 \\
\hline 3 & Truk & 2 & 11,11 & 22.2 \\
\hline 4 & Sepeda & 16 & 11,11 & 172.8 \\
\hline 5 & Becak & 16 & 11,11 & 179.0 \\
\hline \multicolumn{4}{|c|}{ Total LHR Tahun 2021} & 9456.8 \\
\hline
\end{tabular}

(Sumber : Hasil analisa)

Dengan total lalu-lintas harian rata-rata pada tahun 2021, maka dapat diketahui peningkatan jumlah persentasi perkembangan lalulintas ( I \%) yang terjadi pada kurun waktu yang direncanakan 20 tahun mendatang. Dengan batasan nilai (I $\%$ ) sekitar $8 \%$ - $10 \%$ sesuai dengan yang direncanakan.

Menurut Ir. Haminran Saodang (Geometri Jalan) untuk volume lalu lintas harian ratarata yang berkisar antara 5000 - 10.000 smp/hr maka nilai persentasi peningkatan jalan dipakai sebesar $8 \%$ untuk jumlah penduduk yang kurang dari 1 juta. Tabel 3 dan 4

Tabel $\mathbf{3}$ perhitungan smp kendaraan

\begin{tabular}{|c|c|c|c|c|}
\hline No. & $\begin{array}{c}\text { Jenis } \\
\text { Kendaraan }\end{array}$ & $\begin{array}{c}\text { LHR } \\
2021\end{array}$ & $\begin{array}{c}\text { Nilai } \\
\text { eqivalen } \\
\text { SMP }\end{array}$ & $\begin{array}{c}\text { Jumlah } \\
\text { SMP } \\
2021\end{array}$ \\
\hline 1 & $\begin{array}{c}\text { Sepeda } \\
\text { Motor }\end{array}$ & 7981.5 & 1,00 & 7981.5 \\
\hline 2 & Mobil & 1101.2 & 0,25 & 275.3 \\
\hline 3 & Truk & 22.2 & 1,20 & 26.64 \\
\hline
\end{tabular}




\begin{tabular}{|c|c|c|c|c|}
\hline 4 & Sepeda & 172.8 & 0,80 & 138.24 \\
\hline 5 & Becak & 179.0 & 0,80 & 143.2 \\
\hline \multicolumn{7}{|c|}{ Total LHR Tahun 2021 } & 8564.88 \\
\hline
\end{tabular}

(Sumber : Hasil analisa)

Tabel 4 Perhitungan Lalu-Lintas Harian Rata Rata 2021

\begin{tabular}{|c|c|c|c|c|}
\hline No. & $\begin{array}{c}\text { Jenis } \\
\text { Kendaraan }\end{array}$ & $\begin{array}{l}\text { LHR } \\
2021 \\
\end{array}$ & $1 / \mathrm{K}$ & $\begin{array}{r}\text { LHR } \\
2041 \\
\end{array}$ \\
\hline 1 & $\begin{array}{c}\text { Sepeda } \\
\text { Motor }\end{array}$ & 7981.5 & 0,08 & 638.5 \\
\hline 2 & Mobil & 1101.2 & 0,08 & 88.1 \\
\hline 3 & Truk & 22.2 & 0,08 & 1.776 \\
\hline 4 & Sepeda & 172.8 & 0,08 & 13.8 \\
\hline 5 & Becak & 179.0 & 0,08 & 14.3 \\
\hline \multicolumn{4}{|c|}{ Total LHR Tahun 2041} & 756.5 \\
\hline
\end{tabular}

\subsubsection{Mutu Beton Rencana}

Berdasarkan Pedoman Perencanaan Perkerasan Kaku, kuat tarik lentur beton disarankan $40 \mathrm{Kg} / \mathrm{cm}^{2}$ (dalam keadaan memaksa dapat digunakan kuat tarik lentur $30 \mathrm{Kg} / \mathrm{cm}^{2}$ ). Dengan persamaan hubungan kuat tarik dan kuat tekan, maka pada perencanaan tebal perkerasan beton ini penulis merencanakan mutu beton dengan kuat tekan 28 hari sebesar $350 \mathrm{Kg} / \mathrm{cm}^{2}$ (K350).

Dimana :

$$
\begin{aligned}
\mathrm{MR}_{28}= & \frac{\sigma_{b k 28}}{11}+9 \\
\mathrm{MR}_{28}= & \frac{350}{11}+9
\end{aligned}
$$

$M_{28}=40,82 \mathrm{~kg} / \mathrm{cm}^{2}>40 \mathrm{~kg} / \mathrm{cm}^{2}$ (Kuat tarik lentur beton yang disarankan)

\subsubsection{Beban Lalu Lintas Rencana}

Berikut adalah cara menentukan beban lalu lintas rencana.

1. Jumlah sumbu kendaraan niaga (JSKN)

a. Data kendaraan yang melintasi jalur yaitu jenis kendaraan mobil Truk $1.2 \mathrm{~L}$ ( 8,3 ton) dengan jumlah kendaraan 30 , sumbu 60 , beban sumbu depan 2,822 ton, belakang 5,478 ton, konfigurasi sumbu depan STRT belakang STRG

b. Menghitung Jumlah Sumbu Kendaraan Niaga (JSKN) Selama Umur Rencana 20 Tahun adalah sebagai berikut :

$\mathrm{JSKN}=365 \times \mathrm{JSKNH} \times \mathrm{R}$

$$
\begin{aligned}
& \text { Faktor Pertumbuhan }(R)=\frac{(1+\mathrm{i})^{\mathrm{UR}}-1}{\mathrm{i}} \\
& \mathrm{R}=\frac{(1+0,08)^{20}-1}{0,08} \\
& \mathrm{R}=\quad 45,762
\end{aligned}
$$

$$
\begin{aligned}
& \text { Sehingga diperoleh } \\
& \begin{aligned}
\text { JSKN } & 365 \times 60 \times 45,762 \\
& =1,002,187.02 \text { Kendraan }
\end{aligned}
\end{aligned}
$$

2. Jumlah repetisi beban

a. Persentase Beban Sumbu

Persentase beban sumbu kendaraan adalah Persentase masing-masing kendaraan terhadap jumlah total sumbu.

$\%$ beban sumbu $=\frac{\text { Volume kendaraan }}{\text { JSKNH }} \times 100 \%$

$$
\begin{aligned}
& =\frac{30}{60} \times 100 \% \\
& =50
\end{aligned}
$$

b. Jumlah Repetisi Yang Akan Terjadi Selama Umur Rencana Jumlah Repetisi $=$ JSKN $\times$ \%beban sumbu $\times \mathrm{C}$

$$
\begin{aligned}
& =1,002,187.02 \times 50 \times 0,50 \\
& =25,054,675.45
\end{aligned}
$$

\subsubsection{Kekuatan Tanah Dasar}

Daya dukung tanah dasar ditentukan dengan pengujian CBR sesuai dengan SNI 03-1731-1989 atau CBR laboratorium sesuai dengan SNI 03-1744-1989. Masing-masing untuk perencanaan tebal perkerasan lama dan perkerasan jalan baru. Apabila tanah dasar mempunyai nilai CBR lebih kecil dari 2 $\%$, maka harus di pasang pondasi bawah yang terbuat dari beton kurus (Lean-Mix Concrete) setebal $15 \mathrm{~cm}$ yang dianggap mempunyai nilai CBR tanah dasar efektif 5 $\%$.

Pada perencanaan perkerasan kaku Jalan Tembilahan - Terusan Mas ini Penulis mengasumsikan data $\mathrm{CBR}=0 \%, 5 \%, 10 \%$, $15 \%$ yang mana pada CBR $0 \%$ akan di pasang pondasi bawah yang terbuat dari beton kurus (Lean-Mix Concrete) setebal 15 $\mathrm{cm}$ yang dianggap mempunyai nilai CBR tanah dasar efektif $5 \%$ sehingga perhitungan dimulai pada CBR tanah dasar $5 \%$.

Jadi untuk menentukan nilai k (subgrade reaction) dapat dilihat pada berikut ini.

$\mathrm{M}_{\mathrm{R}}=1.500 \times \mathrm{CBR}$

$M_{R}=1.500 \times 5 \%$

$M_{R}=75$

$$
\text { Maka : } \begin{aligned}
\mathrm{k} & =\frac{M_{R}}{19,4} \\
\mathrm{k} & =\frac{75}{19,4} \\
\mathrm{k} & =3,86 \mathrm{~kg} / \mathrm{cm}^{2}
\end{aligned}
$$

\subsubsection{Tebal Pelat Beton}

Tebal pelat beton Sebagai langkah awal direncanakan ketebalan pelat beton $15 \mathrm{~cm}$ setelah dianalisa didapatlah jumlah Fatigue yang terjadi $0 \%<100 \%$, maka perhitungan 
sudah cukup dan tebal plat $15 \mathrm{~cm}$ dapat digunakan.

\subsubsection{Gambar Tebal Perkerkerasan Kaku}

Hasil dari perhitungan menggunakan metode Bina Marga pada perencanaan tebal perkerasan kaku dapat digambarkan susunan tebal perkerasannya seperti terlihat pada gambar 4

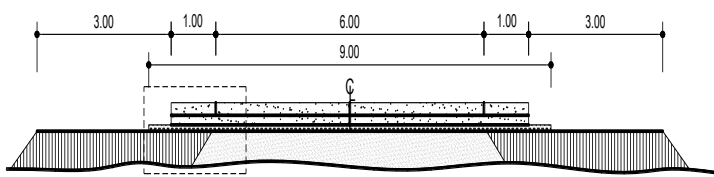

Gambar 4. Potongan melintang (Sumber : Hasil analisis)

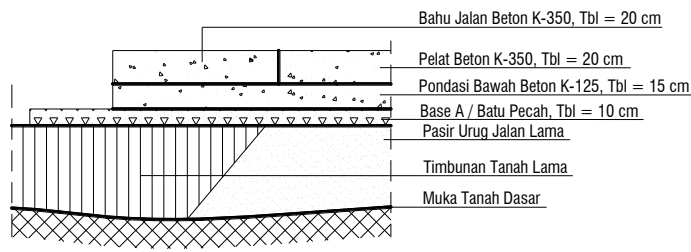

Gambar 5. Detail Susunan Tebal Perkerasan Kaku

(Sumber : Hasil analisis)

\subsection{Rencana Anggaran Biaya}

Rencana angaran biaya pada tebal perkerasan terbagi atas 2 (dua) bagian yaitu biaya konstruksi dan biaya perawatan. Pada perencanaan tebal perkerasan ini penulis hanya menghitung biaya konstruksi. Biaya konstruksi merupakan biaya yang dibutuhkan dalam melaksanakan suatu proyek dari awal sampai dengan selesainya masa pembangunan.

Perencanaan berdasarkan analisa tebal perkerasan kaku dimana pondasi bawah beton $\mathrm{K}-125$ tebal $15 \mathrm{~cm}$, tebal plat beton menggunakan K-350 tebal $20 \mathrm{~cm}$, maka didapat tebal perkerasan kaku $35 \mathrm{~cm}$, dan panjang jalan yang di rencanakan 2,877 km serta anggaran biaya yang dibutuhkan dalam pembangunan Jalan Tembilahan Terusan Mas sebesar Rp 25,035,692,000,-.

\section{KESIMPULAN}

Adapun kesimpulan yang diperoleh dari hasil penelitian dan pembahasan perhitungan perbandingan analisa konstruksi perkerasan kaku pada perencanaan tebal perkerasan pada ruas jalan Tembilahan Terusan Mas yaitu sebagai berikut :

1. Perencanaan tebal perkerasan dengan panjang jalan 2,877 meter, jalan yang direncanakan adalah jalan lokal dengan lebar jalan 8 meter termasuk bahu jalan, maka jumlah Lintas Harian Rencana (LHR) untuk jalan lokal yaitu 8564.8 kendaraan/hari.

2. Perencanaan tebal perkerasan pada konstruksi perkerasan kaku Beton Bersambung Tanpa Tulangan (BBTT) dari hasil analisis penelitian dalam tugas akhir dengan menggunakan Metode Bina Marga diperoleh tebal perkerasan masing-masing lapisan sebagai berikut

a. Lapisan plat beton (Beton K-350) dengan ketebalan adalah $20 \mathrm{~cm}$

b. Lapisan pondasi bawah (Beton K125) dengan ketebalan adalah 15 $\mathrm{cm}$

\section{DAFTAR PUSTAKA}

\section{Buku}

[1] Ardiyansyah, (2020). Perencanaan sistem drainase (studi kasus jalan sungai beringin kecamatan Tembilahan kabupaten indragiri hilir). Tembilahan : Selodang Mayang

[2] Clarkson. H. Oglesby, R. Gary. Hicks. (1982). Teknik Jalan Raya. Jakarta : Erlangga.

[3] Departemen Pekerjaan Umum, Direktorat Jendral Bina Marga. (1997). Tata Cara Perencanaan Geometrik Jalan Antar Kota. Jakarta

[4] Departemen Permukiman \& Prasarana Wilayah, Pd T-14-2003, Perencanaan Perkerasan Jalan Beton Semen.

[5] Direktorat Jendral Bina Marga (1997) Manual Kapasitas Jalan Raya Indonesia Penerbit : Jakarta Selatan

[6] Hardiyatmo, Hary Christady (2009). Pemeliharaan Jalan Raya- Perkerasan Drainase Longsoran. Yogyakarta Penerbit Gajah Mada University Press.

[7] Hardiyatmo, Hary Christady (2010). Stabilisasi Tanah untuk Perkerasan Jalan. Yogyakarta : Penerbit Gajah Mada University Press.

[8] Hardiyatmo, Hary Christady (2011). Perancangan Perkerasan Jalan \& Penyelidikan Tanah-Perkerasan AspalPerkerasan Beton-Sistem Cakar Ayam Modifikasi-Sistem Pelat Terpaku. 
Yogyakarta : Penerbit Gajah Mada University Press.

[9] Mochtar, I.B. (2002). Aspek Perencanaan Jalan Beton Semen)

[10] Pd-T-12-2004-B Penempatan marka jalan oleh ; Departemen Pekerjaan Umum

[11] Shirley L. Hendarsin (2000). Penuntun Praktis Perencanaan Teknik Jalan Raya Penerbit, Jurusan Teknik Sipil

Politeknik Negeri Bandung.

[12] Silvia Sukirman, (2003). Dasar - Dasar Perencanaan Geometrik Jalan. Penerbit Nova, Bandung

[13]SNI DT - 91- 0008 - (2007) Tata Cara Perhitungan Harga Satuan Pekerjaan Beton, oleh Dept Pekerjaan Umum

[14]SNI DT - 91- 0008 - 2007 Tata Cara Perhitungan Harga Satuan Pekerjaan Beton, oleh Dept Pekerjaan Umum

[15] Sukirman Silvia, (1999), Perkerasan Lentur Jalan Raya, Penerbit Nova, Bandung.

[16] Suryadharma, Hendra \& Benidiktus Susanto. (1999). Rekayasa Jalan Raya. Yogyakarta : Penerbitan Universitas Atma Jaya.

[17] Suryawan, Ari. (2013). Perkerasan Jalan Beton Semen Portland (Rigid Pavement). Yogyakarta : Beta Offset Yogyakarta.

\section{Skripsi / Tesis / Disertasi}

[1] Helem, Sunarto (2016). Perencanaan Tebal Perkerasan Kaku (Rigid Pavement) Study Kasus Peningkatan Jalan Gerilya parit 6 (enam) - Jalan Taman Makam Pahlawan parit 6 (enam). Tugas Akhir Teknik Sipil-Universitas Islam Indragiri, Tembilahan

[2] Saleh, Nova (2013). Perencanaan Tebal Perkerasan Pada Ruas Jalan Parit $21 \mathrm{Ke}$ Sungai Getek Tembilahan. Tugas Akhir Teknik Sipil-Universitas Islam Indragiri, Tembilahan

[3] Yupi, Ardianto (2017). Menentukan Nilai CBR Menggunakan Alat DCP Dalam Grafik dan Persamaan Fungsi. Skripsi-v 